\title{
HBsAg ARAŞTIRILMASINDA ELISA VE RPHA YÖNTEMLERININ DUYARLILIKLARI
}

Aydın Karaaslan*

Viral hepatitlerin birbirinden ayırt edilmesinde ve özellikle Hepatit B Virus (HBV) portörlerinin saptanmasında HBsAg'nin önemi anlaşıldıktan sonra, bu antijenin ortaya çıkartılabilmesi için Immunodiffusion (ID), Counterimmunoelectrophoresis (CIEP), Complement Fixation (CF), Rheophoresis (RP), Reversed passive latex agglutination (RPLA), Passive haemagglutination (PH), Immune adherence haemagglutination (IAH), Immune electron microscopy (IEM), Immunoflurescence microscopy (IMF), Reversed passive haemagglutination (RPHA), Radioimmunoassay (RIA), Enzyme Immunoassay (EIA) gibi yöntemler geliştirilmiştir (1).

HBsAg ilk kez Blumberg tarafından ID yöntemi kullanılarak ortaya çıkarılmıştır (1).

RPHA, anti-HBs ile kaplanmış insan, hindi ya da koyun eritrositlerinin, HBsAg varlığında agglutine olması temeline dayanan, çabuk sonuç verebilen, basit ve ucuz bir yöntemdir (25). Romatoid Faktör, Forsman antikorları ve İnfeksiyöz Monoükleozise karşı gelişmiş spesifik antikorlarm serumda bulunması durumunda yalancı pozitif sonuçlar ortaya çıkabilmektedir. Bu nonspesifik faktörler, anti-HBs içermeye nimmunglobulinle kaplanmış eritrositler kullanılarak yapılan absorbsiyon işleminden sonra uzaklasstırılabilmektedir. Absorbsiyondan sonra test yeniden uygulandığında yalancı pozitif örnekler negatifleşecek, gerçek pozitif örnekler ise pozitif kalacaktır. Ancak, zayıf gerçek pozitif örnekler absorbsiyondan sonra, nadir de olsa negatif olarak sonuçlanabilmektedir. Eğer serum çok fazla miktarda nonspesifik faktör içeriyorsa absorbsiyondan sonra bile gerçek negatif örnek,

\footnotetext{
" A.Ü. Tıp Fakültesi Mikrobiyoloji Anabilim Dalı, Öğretim Görevlisi.

Geliş Tarihi : 15 Temmuz 1993 Kabul Tarihi : 2 Mart 1994
} 
hala pozitif olarak kalabilmektedir $(25,27)$. Yalancı pozitifliğin yanında RPHA yöntemi ile yalancı negatif sonuçların da ortaya çıktığı bildirilmektedir (25).

RPHA'nın ELISA ve RIA'dan daha az duyarlı olması, nonspesifik reaksiyonlara sık rastianması, sonuçların kontrolü için absorbsiyon veya doğrulayıcı yöntemlere gereksinim göstermesi gibi dezavantajlarının olmasına karşın (21), Dünya Sağlık Örgütü (DSÖ) tarafından HBsAg taramasında kullanlacak herhangi bir testin en az RPHA kadar duyarlı olması gerektiği bildirilmektedir $(1,9)$.

Günümüzde, HBsAg aranmasında en duyarlı yöntem RIA'dır (29) . Ancak yapılan çeşitli çalışmə.lar ELISA'nın RIA kadar duyarlı olabileceğini göstermiştir $(7,30)$. Ayrıca ELISA daha ucuz ve kolay, radyoaktivite tehlikesi olmayan, reaktanları uzun süre dayanabilen kullanışlı bir testtir (9).

ELISA kullanıminda deneyimin ileri derecede artması ve monoklonal antikorların kullanılmasıyla nonspesifik reaksiyonlar önemli derecede azaltılmıştır (22). Yalancı pozitif sonuçlar çoğunlukla teknik işlemdeki hatalardan, çok az oranda da insan serum ya da plazmasınin kullanilan monoklonal antikorlarla reaksiyona girmesinden kaynaklanmaktadır. Bu sorun nöiralizasyon yapılarak büyük ölçüde engellenebilmektedir (30).

Üçüncü jenerasyon testleri olarak tanımlanan RIA, ELISA ve RPHA arasinda tarama testi olarak en uygun yöntemin ELISA olduğu bildirilmektedir (15).

Bu çalışmada, RPH Ave ELISA yöntemlerinin duyarlılıkları karşılaştırılmıştır.

\section{MATERYAL VE METOD}

Bu çalışmada, Ankara Üniversitesi Tıp Fakültesi İbn-i Sina Hastanesi Kan Merkezine bașvuran, sağlıklı, sarılık geçirme ve kan transfüzyonu anamnezi olmayan 1553 donör serumunda RPHA ve ELISA yöntemleri ile HBsAg araştırilmıştır.

$\mathrm{Bu}$ donörlerden alınan 8-10 CC kenın, steril koşullarda hemolizsiz olarak, serumları ayrılmış, kan merkozimizde hemen RPHA testi yapılmıştır. Serumun kalan kısmı, derin dondurucuda, -20 derecede saklanmış, Mikrobiyoloji Anabilim Dalı ELISA laboratuarında, mikro-ELISA yöntemi ile incelenmiştir. 
Kan merkezimizde bulunan, Organon Teknika firmasına ait «Hepanosticon 3" RPHA kiti kullanılmıştır.

Mikrosistem ELISA yöntemi ile Wellcozyme-HBsAg kitleri (Wellcome Laboratories) kullanılarak, RPHA ile taranmış serumların tamamı yeniden test edilmiştir.

\section{BULGULAR}

ELISA ile \% 7.28 (113/1553) ve RPHA ile \% 6.63 (103/1553) HBsAg pozitifliği bulunmuştur. ELISA, RPHA testinden \% 0.65 daha fazla HBsAg pozitifliği göstermiştir. ELISA ile doğrulanarak RPHA'nın duyarlılığ $\% 89.38$ ve spesifitesi ise \% 99.86 olarak saptanmıştır. RPHA ile \% $10.61(12 / 113)$ yalanci negatiflik ve \% $1.94(2 / 103)$ yalancı pozitiflik saptanmıştır. RPHA ile negatif bulunan 12 serumda, ELISA ile HBsAg pozitif saptanmış ve bu sonuç yalancı negatiflik olarak değerlendirilmiştir. Yine RPHA ile 2 serumda bulunan HBsAg pozitifliği ELISA ile negatif olarak saptandığı için bu da yalancı pozitiflik olarak kabul edilmiştir. Bu sonuçlar Tablo I'de gösterilmiştir.

Tablo I : ELISA ve RPHA testlerinin değeriendirilmesi

\begin{tabular}{lrrrrrrr}
\hline & \multicolumn{3}{c}{ PozisA HBsAg } & \multicolumn{3}{c}{ Negatif } & \multicolumn{2}{c}{ Toplam } \\
RPHA HBsAg & \multicolumn{2}{c}{ Sayı } & $\%$ & \multicolumn{2}{c}{ Sayı } & $\%$ & \multicolumn{2}{c}{ Sayı } & $\%$ \\
\hline Pozitif & 101 & 98.06 & 2 & 1.94 & 103 & 6.63 \\
Negatif & 12 & 0.83 & 1438 & 99.17 & 1450 & 93.37 \\
\hline Toplam & 113 & 7.28 & 1440 & 92.72 & 1553 & 100 \\
\hline
\end{tabular}

HBsAg pozitifliğini saptama açısından ELISA, RPHA'ya göre istatistiksel olarak anlamlı derecede daha duyarlı bulunmuştur $\left(\mathrm{x}^{2}=5.78, \mathrm{p}<0.05\right)$.

\section{TARTIŞMA VE SONUÇ}

HBV taşıyıcıları taşıyıcıları bulaş kaynağı olmaları nedeniyle, infeksiyonun yaylmasinda önemli rol oynamaktadırlar. Kan ve kan ürünleri almak zorunda olan hastaların Post Transfüzyon Hepatit B'den korunabilmesi için, tüm dünyada, kan donörleri HBsAg pozitifliği yönünden taranmaktadırlar $(1,16)$. Bu amaç için kullanılacak 
tekniklerin yalancı pozitif ve yalancı negatif sonuçlarının mümkün olduğunca az, duyarlılıklarının ise fazla olması gerektiği önemle vurgulanmaktadır (25).

Yurt içindeve yurt dışında, çalışma konusunu kan donörlerinin oluşturduğu bir çok çalışma bulunmaktadır (9). HBsAg pozitifliğini saptamaya yönelik çalışmalarda ya tek ya da birkaç teknik kullanılarak, bunların duyarlılıkları, özgüllükleri ile yalancı reaksiyon verme özellikleri incelenmiştir (27). Sonuçta üçüncü jenerasyon testleri olarak adlandırılan RIA, ELISA ve RPHA yöntemlerinin, HBsAg seropozitifliğini tesbit etmede, ID ve CIEP gibi birçok yöntemden daha duyarlı olduğu anlaşılmış bulunmaktadır $(19,24)$. Duyarlılıkları fazla olan testler ile çalıșlırken yöntemin doğru bir şekilde uygülanmasıyla non spesifik reaksiyonların azaltılabileceği ancak tam olarak ortadan kaldırılamayacağı bildirilmektedir (22). Bunun yanında aynı yönteme ait değişik preparatlar arasında bile duyarlılık ve non spesifik reaksiyon oluşturma özellikleri yönünden farklılıklar olabilmektedir (27).

Yurdumuzda, kan donörlerinde, 1971 - 1978 yılları arasında ID tekniği ile Ertuğrul ve Say (6) \% 3, Tuna ve ark. (18) \% 3.6 ve CIEP tekniği ile Mizan (14) \% 2.7, Özgüven (17) \% 3, Paykoç ve ark. (20) \% 3.1 oranında HBsAg seropozitifliği göstermişlerdir. 1553 kan donörünü kapsayan çalışmamızda RPHA ile \% 6.63 ve ELISA ile \% 7.28 olarak saptadığımız HBsAg seropozitiflik değerinin daha yüksek olduğu görülmektedir. $\mathrm{Bu}$ durum yıllar içinde $\mathrm{HBs} \mathrm{Ag}$ pozitifliğinin artmış olması ve bizim kullandığımız testlerin daha duyarlı oiması ile açıklanabilir.

RPHA ile kan donörlerinde HBsAg seropozitifliğini Erdoğan (5) $\%$ 3.7, Turhanoğlu ve Arıkan (28) \% 4.9, Seber (26) \% 5.8 ve Kahraman (10) \% 6.7 olarak bildirmişlerdir. Bizim RPHA ile bulduğumuz \% 6.63'lük değerin Kahraman'in elde ettiği sonuçla uyumlu diğer çalışmaların sonuçlarından ise yüksek olduğu görülmektedir.

Kan donörlerinde ELISA tekniği ile Arıoğul (2) \% 3.85, Günal (8) $\%$ 8, Kumdalı (11) \% 10, Seber (26) \% 10.07, Balk (3) \% $11.2 \mathrm{HBsAg}$ pozitifliği göstermişlerdir. Bizim ELISA ile bulduğumuz \% 7.28'lik oranı Arıoğul'un değerinden yüksek, Günal'ın değerine yakın ve diğer araştırıcıların değerlerinden daha düşüktür. Tüm bu çalışmalar şehir merkezlerinde yapılmalarına rağmen sosyo ekonomik ve bölgesel koşulların farklılığı sonuçları etkileyebilmektedir (4). Bunun yanında, teknik özelliklerinde elde edilen değerlere yansıyacağı unutulmamalıdir (22). 
Kumdalı ve Mutlu (12), Akut Viral Hepatit ön tanısı alan hastalarda, hem RPHA (Hepatest 3) hem de ELISA (Auszyme II) ile HBsAg araştırmışlar ve ELISA ile \% 22 daha fazla pozitiflik yakaladıklarını bildirmişlerdir. Seber (26), değişik tarihlerde iki ayrı grupta RPHA ile \% 5.76 ve ELISA ile \% $10.07 \mathrm{HBsAg}$ pozitifliği saptamış, Łestler arasındaki \% 4.31'iik farkın, EI.ISA'nın duyarlılığından ve pozitiflik oranının zamanla artmış olmasından kaynaklanabileceğini belirtmiştir.

Parah ve ark. (19), Akut Viral Hepatit ön tanısı alan 52 hastada, RPHA ile \% 34, ELISA ile \% 45 ve hastane personelinde RPHA ile \% 3.5, ELISA ile \% 13.5 HBsAg pozitifliği göstererek ELISA'nın daha duyarlı bir teknik olduğunu ve RPHA'dan \% 10 daha fazla pozitiflik saptadığını belirlemişlerdir.

Tayland'da, 892 sağlıklı yetișkin arasında, RPHA ile \% 6.7 ve ELISA ile \% 7.4 HBsAg taşıyıcılığı bulunarak ELISA'nın daha duyarlı olduğu, ancak farkın istatistiksel olarak çok anlamlı olmadığı bildirilmiştir. RPHA'nın duyarlılığ1 \% 91 olarak bulunmuştur (13).

Çalışmamız sonucunda ELISA'nın RPHA'dan istatistiksel olarak anlamlı derecede daha duyarlı olduğu saptanmıștır. ELISA ile doğrulama yaplarak, RPHA tekniği ile \% 1.94 yalancı pozitiflik ve \% 10.61 yalancı negatiflik ortaya çıktığ 1 bulunmuştur. Hepanosticon 3 ile, Schuurs ve Kacaki (25) \% 0.9, Reesink ve ark. (23) \% 1 yalancı pozitiflik belirlemişlerdir. Diğer bir çalışmada da RPHA ile yalancı negatiflik \% 9.1 olarak saptanmıștır (13).

Bu çalışmadan elde edilen sonuçlar, HBV infeksiyon prevalansının azaltılması, aşılanacak bireylerin belirlenmesi ve toplumda taşıyıcılık oranının saptanmasina yönelik araştırmalarda, duyarlılığı yüksek, non spesifik reaksiyon oranı düșük laboratuar yöntemlerinin seçilmesinin önemini ortaya koymaktadır.

\section{ÖZET}

ELISA ve RPHA yöntemleri, HBsAg'ni ortaya çıkarma açısından değerlendirildi. Binbeşyüzelliüç kan donörü tarandı. ELISA ile \% 7.28 ve RPH ile \% 6.63 HBsAg pozitifliği saptandı.

Bu çalıșmada, ELISA'nın RPHA'dan daha duyarlı olduğu bulun$\mathrm{du}(\mathrm{p}<0.05)$.

Anahtar Kelimeler : Kan donörleri, Karşılaştırmalı çalışma, Hepatit B yüzey antijeni. 


\section{SUMMARY}

Sensitivity of ELISA and RPHA methods in investigation of HBsAg

Detection of HBsAg by ELISA and RPHA assessed. The sera of 1553 blood donors were examined. The prevalence of HBsAg by ELISA was \% 7.28 and \% 6.63 by RPHA.

This study revealed that ELISA were more sensitive than RPHA $(\mathrm{p}<0.05)$.

Key Words : Blood donors, Comparative study, Hepatit B surface antigen.

\section{KAYNAKLAR}

1. Advances in Viral Hepatitis : World Health Organization Technical Report Series. $62: 1,1977$.

2. Arıoğul S : Kan donörlerinde HBsAg prevalansı. İnfeksiyon Derg. 1 : 289, 1987.

3. Balık M Saydam GS Aktaş F : Kan donörlerinde HBsAg yaygınlığı. Mavi Bülten $20: 97,1988$.

4. Çakaloğlu Y Ökten A Yalçın S : Türkiye'de hepatit B virusu infeksiyonu seroepidemiyolojisi. T Klin Gastroenterohepatoloji 1: 49, 1990.

¿. Erdoğan Y Dalkılıç E Kılıç H : Erciyes Üniversitesi Tıp Fakültesi Kan Bankası donörlerinde HBsAg ve VDRL çalışmaları. 1. Ulusal İnfeksiyon Hastalıkları Kongre Kitabı. İzmir, s. 252, 1987.

6. Ertuğrul M Say B : Australian antigen in Turkey. Lancet 1:1302, 1971.

7. Fields HA Davis CL Bradley DW : Experimental conditions affecting the sensitivity of ELISA for detection of HBsAg. Bull WHO 61: 135, 1983.

8. Günal AR : Ankara Numune Hastanesi kan donörlerinde $\mathrm{HBsAg}$ ve anti-HBc araştırılması. Uzmanlık Tezi. Numune Hastanesi. Ankara, 1989.

9. Kacaki J Wolters G Kuijpers L et al : Result of a multicentre clinical trial of the solidphase enzyme immunoassay for HBsAg. Vox Sang $35: 65,1978$.

10. Kahraman İ : Kan denörlerinde HBsAg pozitiflig̈i. Uzmanlık Tezi Numune Hastanesi. Ankara, 1982. 
11. Kumdalı A Mutlu G : Kan donörlerinde, hemodiyaliz hastalarında sağlık personelinde, hepatit ön tanılı hastalarda ve diğer gruplarda hepatit B yüzey antijeninin ELISA yöntemiy!e araştırılması. 1. Ulusal İnfeksiyon Hastalıkları Kongre Kitabı. İzmir, s. 251, 1987.

12. Kumdalı A Mutlu G : Hepatitis B yüzey antijeninin aranmasında pasif hemagglütinasyon ve solid-phase enzyme immunoassay yöntemlerinin karşılaştırılması. Akd. Ü. T. F. Derg. 2 : 119, 1984.

13. Louisirirotchanakul S Wasi C Sakulkoo P et al : Sensitivity of ELISA and hemagglutination test for hepatitis B markers. J Med Ass Thailand 69 : 279, 1986.

14. Mizan N : Kan bağıșcılarımızda Avustralya antijeni. Mikrobiyol Bült 10 : 339, 1976.

15. Nath N Dodd RY Fang CT : Enzyme-linked immunoassay for HBsAg. Transfusion $23: 45,1983$.

16. Nurse GT Babona DV : Hepatitis B and blood transfusion. Lancet 1 (letter) : 107,1988

17. Özgüven Ö Manoğlu K Sebik F : Türk kan donörlerinde hepatitis B surface antijeni sıklığı. Ege ÜTF Derg. 17 : 9, 1978.

18. Palabıyıkoğlu E : Toplum sağlığında akut viral hepatitislerin önemi. KLIMIKK Derg. $1: 38,1988$.

19. Parab VV Talawadekar NN Kale VV et al : Comparative study of methods of detection of HBsAg. J Postgrad Med 35: 83, 1989.

20. Paykoç Z Uzunalimoğlu Ö Alptuna E et al : Hepatitis antijeni : Türk kan donörlerinde HBsAg ve transfüzyona bağlı hepatitin önlenmesi. AÜTFM 27: 703, 1974.

21. Rapid Laboratory techniques for the diagnosis of viral infections. WHO Technical Report Series 661: 1, 1981.

22. Ratnam S Stead F Head CB : False-pozitive results with third generation monoclonal HBsAg enzyme immunoassay. J Clin Microbiol 27 : 2102, 1989.

23 Reesink HW Lafeber-Schut LJ Aaij C et al : Comparison of sic third-generation tests for the detection of HBsAg. Vox Sang $39: 61,1980$.

24. Saha V John TJ Dhamodaran S et al : Highly sensitive screening tests for HBsAg in transfusion centres of developing countries. BMJ $297: 334,1988$.

25. Schuurs AHWM - Kacaki J : Reversed haemagglutination test for the detection of HBsAg. Vox Sang 27 : 97, 1974.

26. Seber E : Kan donörlerinde HBsAg taraması. İnfeksiyon Derg 1 : 185, 1987. 
27. Stancek D Blaskovicova H Holenova C et al : Non-spesific and false-negative reaction in detection of HBsAg. Acta Virol 26 : 169, 1982.

28. Turhanoğlu M Arıkan E : Güneydoğu Anadolu bölgesinde değişik gruplardaki hepatit B yüzey antijen ve antikorunun insidansı Dicle ÜTF Derg 1 : 28, 1987.

29. Walsh JH Yalow R Berson SA : Detection of Australia antigen and Antibody by means of radioimmunoassay teshniques. JID $121: 550,1970$.

30. Wei R Knight GJ Zimmerman DH et al : Solid-phase enzyme immunoassay for HBsAg. Clin Chem $23:$ 813, 1977. 